\title{
ERRATUM
}

James L. Whiteside

\section{The now and the not yet of pelvic floor dysfunction}

Published online: 9 October 2004

(C) International Urogynecological Association 2004

\section{Int Urogynecol J (2004) \\ DOI 10.1007/s00192-004-1233-x}

In the last paragraph, the following sentence should have read: Women develop these problems and we fail to completely know the etiology, the best means of assessment and the best means of correction.

The online version of the original article can be found at http:// dx.doi.org/10.1007/s00192-004-1233-x

\section{J. L. Whiteside}

Department of Obstetrics and Gynecology,

Division of Urogynecology and Reconstructive Pelvic Surgery,

Dartmouth-Hitchcock Medical Center,

One Medical Center Drive, Lebanon,

New Hampshire 03756, USA

E-mail: James.L.Whiteside@Hitchcock.org

Tel.: + 1-603-6539312

Fax: + 1-603-6500902 